\section{Evaluation of a brief tailored motivational intervention to prevent early childhood caries}

Ismail AI, Ondersma S, Willem Jedele JM, Little RJ, Lepkowski JM. Evaluation of a brief tailored motivational intervention to prevent early childhood caries. Community Dent Oral Epidemiol 2011; 39: 433-448. (C) 2011 John Wiley \& Sons A/S

Abstract - Objectives: This pragmatic randomized trial evaluated the effectiveness of a tailored educational intervention on oral health behaviors and new untreated carious lesions in low-income African-American children in Detroit, Michigan. Methods: Participating families were recruited in a longitudinal study of the determinants of dental caries in 1021 randomly selected children (0-5 years) and their caregivers. The families were examined at baseline in 2002-2004 (Wave I), 2004-2005 (Wave II) and 2007 (Wave III). Prior to Wave II, the families were randomized into two educational groups. An interviewer trained in applying motivational interviewing principles (MI) reviewed the dental examination findings with caregivers assigned to the intervention group (MI + DVD) and engaged the caregiver in a dialogue on the importance of and potential actions for improving the child's oral health. The interviewer and caregiver watched a special 15-minute DVD developed specifically for this project based on data collected at Wave I and focused on how the caregivers can 'keep their children free from tooth decay'. After the MI session, the caregivers developed their own preventive goals. Some families in this group chose not to develop goals and were offered the project-developed goals. The goals, if defined, were printed on glossy paper that included the child's photograph. Families in the second group (DVD-only) were met by an interviewer, shown the DVD, and provided with the project's recommended goals. Both groups of families received a copy of the DVD. Families in the MI + DVD group received booster calls within 6 months of the intervention. Both caregivers and the children were interviewed and examined after approximately 2 years (Wave III: 2007). Results: After 6-month of follow-up, caregivers receiving MI + DVD were more likely to report checking the child for 'precavities' and making sure the child brushes at bedtime. Evaluation of the final outcomes approximately 2 years later found that caregivers receiving the MI + DVD were still more likely to report making sure the child brushed at bedtime, yet were no more likely to make sure the child brushed twice per day. Despite differences in one of the reported behaviors, children whose caregivers received the motivational intervention did not have fewer new untreated lesions at the final evaluation. Conclusions: This study found that a single motivational interviewing intervention may change some reported oral health behaviors, it failed to reduce the number of new untreated carious lesions.
Amid I. Ismail ${ }^{1}$, Steven Ondersma ${ }^{2}$, Jenefer M. Willem Jedele ${ }^{3}$, Roderick J. Little $^{3}$ and James M. Lepkowski ${ }^{3}$

${ }^{1}$ Kornberg School of Dentistry, Temple University, Philadelphia, PA, ${ }^{2}$ School of Medicine, Wayne State University, Detroit, $\mathrm{MI},{ }^{3}$ School of Public Health and Institute for Social Research, University of Michigan, Ann Arbor, MI, USA

Key words: early childhood caries; motivational interviewing

Amid I. Ismail, Temple University's Kornberg School of Dentistry, 3223 N. Broad Street, Philadelphia, PA 19140, USA Tel.: +1 2157072799 e-mail: ismailai@dental.temple.edu

Submitted 31 March 2010; accepted 21 February 2011
Dental caries is the most common chronic childhood disease (1). Early childhood caries (ECC) occur after the eruption of first teeth (2), and it represents a significant problem for low-income and minority populations in the US and Canada (3-9). Children with ECC are more likely to experience disease in permanent teeth (10-12), pain, and lowered self-esteem; untreated caries can also lead to lifelong oral health problems (13).

Behavioral change is necessary to prevent ECC and protect children's teeth (14-17). Interventions 
during pregnancy or early childhood have shown considerable effects on the long-term health and development of children (18). Children whose mothers display a lack of knowledge about some determinants and means of prevention of ECC have higher caries prevalence and severity than those whose mothers are more informed about determinants and means of prevention of caries $(10,11,19,20)$. However, simply having knowledge about healthy behaviors is often insufficient for changing unhealthy behaviors (21-23).

Motivational Interviewing (MI) is an individualcentered brief counseling technique that uses an empathic, collaborative style to elicit and build on patients' own reasons for change. Four principles guide the implementation of MI: (i) expression of empathy: the counselor understands the individual's feelings without judging; (ii) exploring ambivalence: through open-ended questions, the counselor facilitates the individual's formulation of arguments for changing; (iii) rolling with the resistance: the counselor focuses on creating a new perspective for the importance of change; and (iv) supporting self-efficacy: the counselor facilitates development of the individual's confidence to cope with obstacles and succeed in changing (24). MI has proven efficacious with a range of healthrelated behaviors, including substance abuse, diet and exercise, and medication adherence (25). Metaanalytic reviews have suggested that (i) a single session of MI is associated with significant effects on a range of outcomes $(25,26)$; (ii) MI has a significant impact when compared to no treatment, as well as (and perhaps particularly) when used as a precursor to a more intensive and structured treatment; and (iii) the effects of MI are greatest at the initial follow-up and decline over time $(25,27)$.

Importantly, MI has also shown promise in helping parents decrease a child's risk of developing ECC (12, 24, 25, 28-30). For example, Weinstein et al. showed that children of parents receiving MI had fewer carious surfaces, more fluoride varnish applications, and a lower likelihood of developing new lesions after 2 years than children of parents receiving a pamphlet and watching a video (28). Such an effect is consistent with the importance of caregivers in the realization and continuation of their children's health-related behavior (31-34). Parents decide what a child eats, where a child goes, what activities they participate in, what their physical environment is like, and what sort of emotional environment they live in (35). Parental practices related to seeking health care, smoking, affection/bonding, and nutrition deeply affect health outcomes for that child (18).

The present study was designed to evaluate the effectiveness of a tailored, educational intervention utilizing brief motivational interviewing to promote healthy behaviors, including brushing behaviors, food choices, checking for precavities, and seeing a dentist, and to reduce the development of new untreated decay in low-income African-American children. This is the first study to examine the MI approach for oral health behaviors and dental caries in low-income African-American children. It is also unique in its emphasis on a 'real-world' test of this approach, by (i) utilizing community therapists as interventionists, and (ii) comparing the brief MI intervention to an active control condition.

\section{Methods}

\section{Sample design and selection of families}

The data were collected during the Detroit Dental Health Project (DDHP), a 7-year study designed to identify the determinants of variation in prevalence and incidence of dental caries among low-income African-American children in Detroit (36). At baseline in 2002, a two-stage probability proportionate-to-size sampling design was used to select housing units in the 39 census tracts in the city of Detroit with the highest concentration of residents with family incomes at or below the 250th percentile of the of poverty line (e.g., a family of 4 with an annual income of <\$4 125). All buildings and businesses in 118 randomly selected geographic segments within the census tracts were listed, and a random sample was drawn from the units identified as houses. Housing units with families making <250th percentile of the poverty line and having at least one African-American child aged $<5$ years old were recruited for the study. Of the 1389 families recruited, 1021 were interviewed and examined at a central location in Detroit in 20022003. Only one child aged $0-5$ years per family was selected for inclusion in the study using a random selection process. The selected child's primary caregiver, defined as the individual who makes decisions for the child and is responsible for the child's welfare and health care, was also included in the study. The Health Sciences Institutional Review Board at the University of Michigan granted approval for this study.

The children were randomized either into an intervention group (MI + DVD) or a control or 


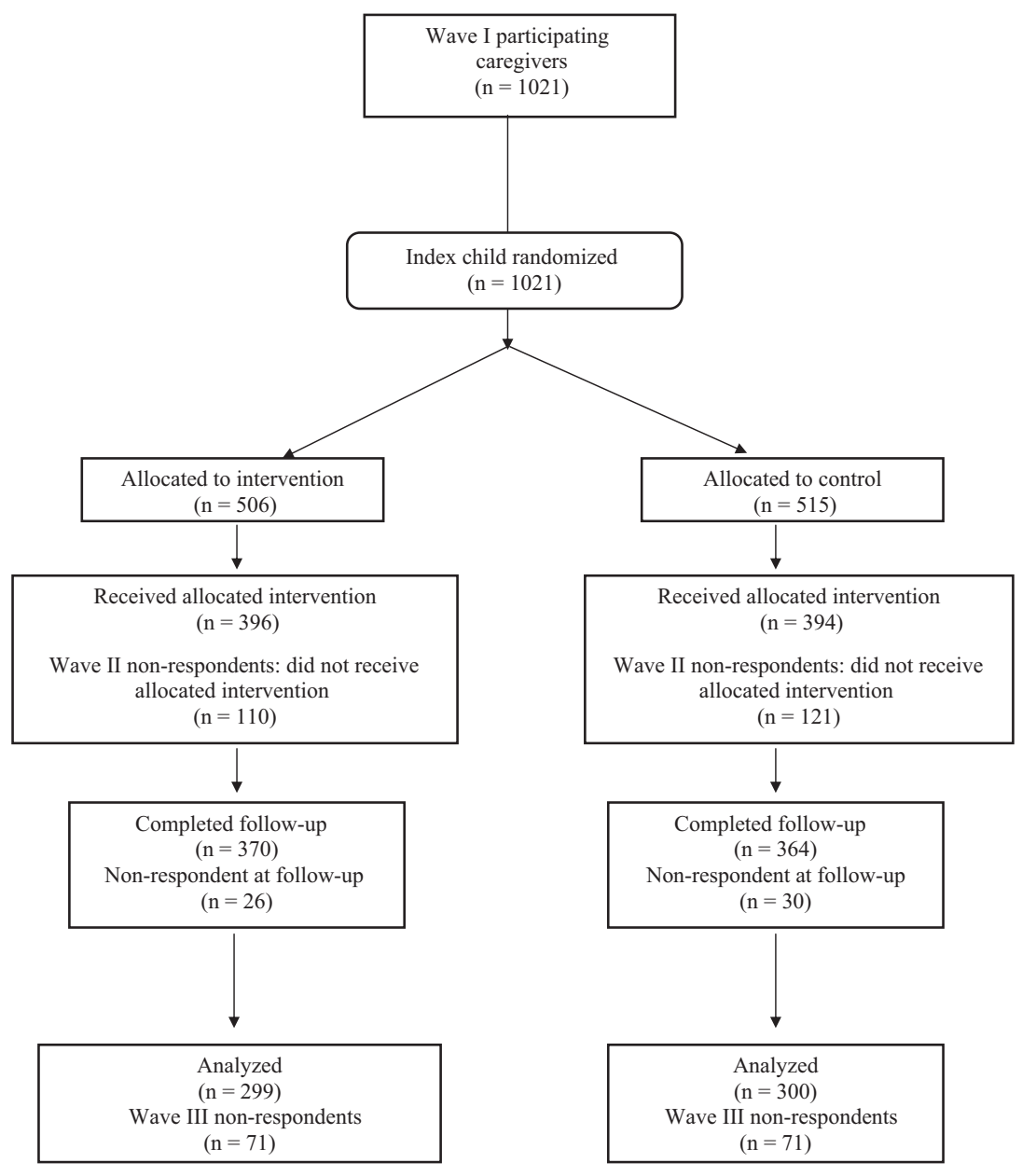

Fig. 1. Participant disposition.

comparison group (DVD-only) (Fig. 1). As a community oral health participatory research project, we have listened to our community partners, and we have made a commitment to the community that we would treat all families with respect and would work for the betterment of the community as a whole. We felt it would be unethical to provide no benefit to the families in the control group; therefore, it was decided that the families in the control group would at minimum watch the educational DVD and receive list of recommendation on how to maintain the oral health of their children. This decision was well received by our Community Advisory Committee, who shared with us their concerns that researchers often conduct research for the purpose of benefitting themselves but not directly for community members.

\section{Randomization}

Prior to Wave II data collection, 1021 children participating in Wave I were stratified by age and caries severity (sound, early carious lesions, cavi- tated carious lesions) as assessed in Wave I. A random number was generated for each child using the RAND function in MS Excel. The random numbers were classified into odd and even numbers, and each child was assigned to one of the two groups. The assignment of the children was masked to participants, project staff with the exception of coordination desk and interviewing staff, examining dentists, and analysts. The randomization process resulted in the assignment of 506 children to an MI + DVD group and 515 to a DVD-only group. Although the children were randomized and their dental outcomes would be the focus of the evaluation, the intervention was administered to the child's caregiver who presented at Wave II. The numbers of children who received the intervention and completed the trial are listed in Figure 1.

\section{DVD intervention component}

After the dental examinations of the child and caregiver in Wave II, the caregiver met with a 
trained MI interviewer (MI + DVD intervention group) or a research assistant (DVD-only control group). In the presence of the research assistant or interviewer, caregivers in both conditions viewed a high-quality, 15-minute educational video specifically designed for the project emphasizing the importance of good oral health in children and demonstrating how the caregiver can keep children free from tooth decay. Development of the video, which was titled 'You can keep your children free from tooth decay', was based on Social Cognitive Theory (37) and was designed to promote selfconfidence among the caregivers to keep their children free from dental caries. The theory postulates that behavior reciprocally influences, and is influenced by, personal as well as social and physical environment factors. As a result, human behavior is based upon the influence of behavioral, cognitive, and cognitive sources of influence.

Using the results from the baseline survey of oral health beliefs combined with qualitative information obtained from focus groups conducted with caregivers prior to the start of this trial, the video addressed the targeted oral health beliefs, good oral health practices, and barriers to achieving good oral health practices. Specifically, the video discussed the process of tooth decay, how to brush children's teeth at various age levels, and how eating habits affect the process of tooth decay. Throughout the video, motivational messages addressing oral health beliefs and barriers to achieving good oral health practices were presented by the actors. The video was produced by a professional media company in Detroit. The video was narrated by a practicing African-American dentist who appeared in the video as the 'dentist'. Other actors were caregivers from Detroit and project staff. The video was designed to be action-oriented with music, images, and movement of the actors.

\section{Training and fidelity of MI interviewers}

Interviewers were master's-level therapists from the community who attended a 2-day training covering the purpose and basic principles of MI as well as practicing MI techniques through roleplaying exercises. Interviewers continued supervised training by an MI expert (Dr. Ondersma) for a period of 4 weeks. All interviews were recorded and analyzed by the expert. During the project, the MI sessions were taped and reviewed by research staff. MI interviewers were provided weekly feedback during data collection. To assess the quality of the educational intervention and to evaluate how well the interviewers applied MI techniques, a randomly selected subset $(n=152,38.4 \%)$ of the taped sessions were scored by project staff trained in MI using the Motivational Interviewing Treatment Integrity (MITI) Code (38). A randomly selected set of 30 taped sessions were scored by the MI trained project staff and by an external group specializing in the use of the MITI to assess the reliability of the project's MITI coding.

\section{$M I+D V D$ intervention group}

For caregivers assigned to the MI + DVD condition, following the video, the MI interviewer engaged the caregiver in a discussion of their thoughts and concerns (if any) regarding their child's oral health, and in particular regarding what changes (if any) they wished to make with respect to their monitoring of their child's oral health. With the caregiver's assent, feedback from their child's dental examination was also reviewed as part of this interview. At the conclusion of the session, all caregivers received a brochure printed on glossy paper that displayed a photograph of their child, and a magnet for placing the brochure in a convenient place at home. The majority of the caregiver who chose to set one or more specific goals for their child's oral health received a glossy brochure listing their goals, and it also displayed the child's photograph. A small number of caregivers $(n=43)$ who chose not to set specific goals were offered a general list of 10 recommendations regarding dietary intake, oral hygiene, and dental check-ups developed by the project printed as well as a glossy brochure with the child photograph. The session ended with a dialogue regarding possible barriers to implementing the personal plan (if any) and how the caregiver planned to overcome those barriers.

Within 6 months of this brief intervention session, which lasted on average 40 minutes, attempts were made to contact the caregivers to review the goals as well as to administer a follow-up questionnaire regarding oral health behaviors, beliefs, and attitudes. The MI + DVD group also received a second copy of the brochure with the child's photograph and the goals 7 months after the intervention and after most of the follow-up questionnaires had been completed.

\section{DVD-only control group}

Caregivers in the control group watched the same educational video and were given a list of instructions on how to promote the oral health of their children. At the end of the video, the 
research assistant provided the caregivers with a glossy-printed brochure that displayed the 10 project recommendations as well as the child's photograph. Caregivers in this condition did not receive any feedback from the dental examination regarding their child's caries/precarious lesions status. Caregivers in the DVD-only group were also administered a follow-up questionnaire within 7 months after the intervention; however, goals were not reviewed, nor was the brochure remailed as it was for the MI + DVD group.

\section{Six-month follow-up evaluation}

The follow-up phone call was scheduled and attempted for all caregivers (MI + DVD and DVD-only) within 6 months of the date the caregiver received the intervention. During the follow-up phone call, a brief questionnaire assessed the caregiver's and child's dental health practices as well as the intermediate impact of the intervention. Reaching every caregiver via phone was not feasible because of the high mobility and frequent phone disconnections of the families; therefore, different approaches were used to reach the families including administering the follow-up questionnaire in the home. On average, caregivers were contacted 28.8 weeks after receiving the intervention, and the majority (60.6\%) were interviewed within the prescribed 6 months after the intervention. Most caregivers were followed-up via phone call (87.1\%). Of the 790 Wave II participants, 734 (92.9\%) were successfully contacted and interviewed during the follow-up period: $370(93.9 \%)$ in the MI + DVD group and 364 (91.9\%) in the DVD-only group.

\section{Booster for intervention group}

Seven months after the completion of the intervention and after the majority of follow-up interviews had been completed, the child-specific brochures were re-mailed only to those assigned to the $\mathrm{MI}+$ DVD group. Those in the MI + DVD group who set goals $(n=326)$ were mailed a brochure with their child's picture and the list of goals they set during the MI session. Those who set no goals and chose to receive the project's standard 10 goals ( $n=46)$ were mailed a brochure with their child's picture and the standard goals. The remaining caregivers who set no goals and chose not to receive the project's standard goals $(n=24)$ were sent no brochure but were offered a chance to receive the goals if they wished by returning a request card, but only one of these caregivers asked for the brochure.
Rationale for independent measures selected in the analysis

Wave II was considered the baseline as the intervention was administered after the questionnaires and dental examination were completed. Individual and neighborhood-level risk factors were initially selected based on the factors determined to be significant predictors of disease in children in previous analyses of the Detroit Dental Health Project data $(6,39-45)$.

\section{Child-level factors}

Child-level factors included the following: child's age (in years); gender ( $1=$ female, $0=$ male); frequency of soda consumption during the past week ( 1 = never, 2 = 1 day, 3 = 2-6 days, 4 = everyday) using the Block Kids Food Frequency Questionnaire (Berkeley, CA, USA); weight-for-age percentiles computed according to the 2000 Centers for Disease Control and Prevention growth charts (46) and categorized into quartiles; having visited a dentist in the past 2 years $(1=$ yes, $0=$ no); and current participation in Head Start $(1=$ yes, $0=$ no). Untreated lesions (noncavitated, cavitated, and total) were assessed at baseline using the International Caries Detection and Assessment System (ICDAS) (47), and the total number of untreated lesions was categorized into quartiles. The ICDAS classifies each tooth surface (pits and fissures, buccal/lingual/mesial/distal separately) into a 7-point scale as follows: $0=$ sound, 1 = first visual change in enamel; 2 = distinct visual change in enamel; $3=$ localized enamel breakdown caused by caries with no visible dentin or underlying shadow; $4=$ underlying dark shadow from dentin with or without localized enamel breakdown; 5 = distinct cavity with visible dentin; and $6=$ extensive distinct cavity with visible dentin. A detailed description of the criteria is available at the ICDAS website: (http://www.icdas.org/elearning.html).

Three of the examiners including the senior trainers were the same throughout the baseline and follow-up examination. Additional examiners were recruited during each wave and trained using a rigorous 2-week training following checks on quality of the quality on monthly bases. Examiners' reliability coefficients were fair to excellent.

\section{Caregiver/family-level factors}

Caregiver- and family-level factors included the following: caregiver's gender $(1=$ female, $0=$ 
male); caregiver's age $(1=14-24$ years, $2=25-$ 34 years, $3=35-44$ years, $4=45+$ years); highest level of education $(1=$ less than high school, $2=$ high school/GED, $3=$ some college or more); household income $(1=$ less than $\$ 10 \mathrm{~K}, 2=\$ 10$ $\$ 19$ 999, $3=\$ 20-\$ 29999,4=\$ 30 \mathrm{~K}$ or more); and religiosity $(1=$ attend religious services at least $1 \times$ per week, $0=$ other). Oral health self-efficacy was measured and calculated as described in Finlayson et al. 2005 and categorized into quartiles. Parenting stress was measured using an existing scale (48) and categorized into quartiles. Fatalism was assessed by rating agreement with the statement 'Most children eventually develop dental cavities' ( 1 = Agree/Strongly agree, $0=$ Disagree/Strongly disagree/Neutral). The number of noncavitated, cavitated, missing, and filled surfaces $\left(\mathrm{D}_{\mathrm{T}} \mathrm{MFS}\right)$ of the caregiver was assessed using the ICDAS criteria. $\mathrm{D}_{\mathrm{T}} \mathrm{MFS}$ was categorized into quartiles for the present analysis. Indicators of a caregiver change between Waves I and II or between Waves II and III ( 1 = change, $0=$ no change $)$ were also included.

\section{Neighborhood-level factor}

A neighborhood disadvantage index was computed according to the formula suggested by Ross and Mirowsky (49). This index was categorized into quartiles ( $1=$ least disadvantaged to $4=$ most disadvantaged).

\section{Behavioral factors}

Behavioral factors included the following: brushing behaviors such as times brushed per day $(1=2 \times$ per day, $0=$ less than $2 \times$ per day); days brushed per week ( $1=7$ days, $0=$ less than 7 days); and days brushed at bedtime ( $1=7$ days, $0=$ less than 7 days). Oral health-related behaviors recording whether or not the caregiver engaged in a particular behavior $(1=$ do this now, $0=$ don't do this now) were included in the analysis as well. These behaviors included providing child with nonsugared snacks, giving the child healthy meals, checking the child for precavities, making sure that the child sees the dentist every 6 months, making sure that the child brushes at bedtime, and assuring that the child brushes twice per day.

\section{MI fidelity summary measure}

An overall measure of fidelity was created to assess any impact the fidelity of the MI session might have had on the behavioral and clinical outcomes. Scores for global ratings of empathy, motivational interviewing spirit, percentage of open questions, and total reflections were summed then standardized. The standardized $z$-scores were then categorized into quartiles to differentiate interviewers on MI fidelity.

\section{Selection of final predictors}

Bivariate analyses were conducted on the Wave II baseline factors, and those factors that were significantly different between the two intervention assignments were included in the models to evaluate the intermediate and final behavioral outcomes as well as the final clinical outcomes. Despite the lack of differences between the two groups at baseline, the measure of self-efficacy was included as a predictor in the final models as it is an important principle of MI, and its inclusion allows for testing any impact of the interaction between level of self-efficacy and group assignment. In addition to these significant factors, a variable to indicate intervention assignment was included.

\section{Clinical outcomes: increments in untreated caries}

That the children of caregivers in the MI + DVD group would have better clinical outcomes at Wave III than children of caregivers in the DVD-only group was the primary a priori hypothesis for this study. Clinical outcomes were defined as the number of new noncavitated, new cavitated, and new untreated lesions. These outcome measures were calculated by comparing the caries status of each tooth surface in Wave III as assessed using ICDAS with its status in Wave II. The examinations followed the same criteria and protocols for training of the examiners. Because of a small number of surfaces with reversals $(0.3 \%$ of the total number of surfaces) which could have occurred by the examiner's error as well as transitions from noncavitated carious lesions to sound tooth surfaces, an adjustment formula suggested by Beck et al. (50) was applied to the calculation of caries increments between Waves 2 and 3 .

\section{Behavioral outcomes}

A secondary hypothesis was that children and caregivers in the MI + DVD group would have better behavioral outcomes than children and caregivers assigned to the DVD-only group. Brushing behaviors of the child were assessed at Wave II (baseline), 6-month follow-up, and Wave III. Behaviors included times brushed during a typical day $(1=2$ or more, $0=$ less than 2$)$; days brushed during a typical week; and days brushed before 
bed ( $1=7$ days, $0=$ less than 7 days). Other behaviors assessed at baseline, 6-month followup, and at Wave III, were whether or not the caregivers adhered $(1=$ do this now, $0=$ don't do this now) to specific oral health practices including providing the child with nonsugared snacks, always giving the child healthy meals, checking for 'precavities', assuring the child sees the dentist every 6 months, assuring the child's teeth are brushed at bedtime, and assuring the child's teeth get brushed twice per day.

\section{Statistical analysis}

Of the 790 participants who returned in Wave II, 396 (78.3\% of those originally assigned) had been assigned to the intervention group (MI + DVD), and 394 (76.7\% of those originally assigned) had been assigned to the comparison group (DVDonly). A total of $654(64.0 \%)$ respondents returned in Wave III: $324(64.0 \%)$ in the MI + DVD group and $330(64.0 \%)$ in the DVD-only group. Of the 654 Wave II participants, 599 caregivers (55.9\%) participated in Wave II and Wave III and were thus included in an intent-to-treat analyses: 299 (55.3\%) in the MI + DVD group and $300(56.3 \%)$ in the DVD-only group. Any potential bias as a result of drop-out was assessed by comparing the same Wave II characteristics included in the models but collected at Wave 1 of respondents and drop-outs within each intervention group.

Intermediate and final behavioral outcomes were evaluated using logistic regressions. The impact of the intervention on the Wave III clinical outcomes was evaluated using negative binomial regressions. Additional analyses including the interaction between group assignment and baseline disease levels were also conducted to determine whether the intervention had a differential impact depending on severity of disease. Analyses were conduced with STATA 10 (Stata Corp, College Station, TX, USA) to account for the complex sample design. All analyses were adjusted with the weight developed to account for unequal probabilities of selection and differential nonresponse.

A small number of missing values $(<4 \%$ for any one item) was imputed using IVEware (51), a SAScallable software application. IVEware imputes missing and nonsubstantive ('don't know' or 'refused') responses using a multiple imputation method in which a sequence of regression models are fit and values are drawn from the predictive distributions. Missing values for dental outcomes were not imputed.

\section{Results}

MI fidelity

Three of the four individual elements included in the global fidelity score can be compared to recommended standards for MI fidelity. Basic proficiency or higher in percent of open-ended questions was reached in $98.4 \%$ of sessions, with a mean $\%$ open-ended question rating of $76.5 \%$. The number of sessions reaching basic proficiency or higher in the global ratings was lower: proficiency or higher for MI spirit and overall empathy was observed in $43.2 \%$ and $26.9 \%$ of all taped sessions, respectively.

\section{Bias analysis}

Results of the bias analysis found minor differences between the respondents and drop-outs with respect to their Wave I characteristics. Respondents assigned to the MI + DVD group were more likely than drop-outs assigned to the MI + DVD group to have ever taken the index child to the dentist (37.8\% and $28.0 \%$, respectively). Significantly, more of the children assigned to the MI + DVD group who dropped-out were male $(53.1 \%$ and $44.5 \%$, respectively). In those assigned to the DVD-only group, the only difference between the respondents and drop-outs was with respect to having ever visited a dentist. Drop-outs were more likely than respondents to have ever taken their child to the dentist (37.7\% and 31.7\%, respectively). No differences in baseline (Wave II) disease levels existed between respondents and drop-outs in either those assigned to the MI + DVD group or those to the DVD-only group.

\section{Baseline (Wave II) characteristics}

Of the 21 baseline characteristics considered, the MI + DVD and DVD-only group differed on only 5 (Table 1). Bivariate analyses show that more children in the MI + DVD group appear to live in more advantaged neighborhoods. More children in the MI + DVD group were reported as having visited the dentist since the last visit (Wave I) to the project's assessment center. More children in the MI + DVD group experienced a caregiver change between Wave I and Wave II. Finally, more children in the MI + DVD group reported brushing twice per day as well as brushing every day at bedtime.

\section{Six-month behavioral outcomes}

Logistic regression models were employed to test the impact of the intervention on the 6-month 
Ismail et al.

Table 1. Baseline (W2) characteristics by intervention assignment

\begin{tabular}{|c|c|c|c|}
\hline & $\begin{array}{l}\mathrm{MI}+\mathrm{DVD} \\
n(\%)\end{array}$ & $\begin{array}{l}\text { DVD-only } \\
n(\%)\end{array}$ & $P$ \\
\hline Total & $299(49.92)$ & $300(50.08)$ & \\
\hline \multicolumn{4}{|l|}{ Neighborhood disadvantage index } \\
\hline Lowest & $79(26.42)$ & $78(26.00)$ & \multirow[t]{4}{*}{0.033} \\
\hline 2 & $72(24.08)$ & $79(26.33)$ & \\
\hline 3 & $62(20.74)$ & $84(28.00)$ & \\
\hline Highest & $86(28.76)$ & $59(19.67)$ & \\
\hline \multicolumn{4}{|l|}{ Child characteristics } \\
\hline \multicolumn{4}{|l|}{ Gender } \\
\hline Male & $133(44.48)$ & $141(47.00)$ & \multirow[t]{2}{*}{0.382} \\
\hline Female & $166(55.52)$ & $159(53.00)$ & \\
\hline Age (years) & 4.63 & 4.51 & 0.353 \\
\hline \multicolumn{4}{|l|}{ Frequency of soda consumption } \\
\hline Never & $94(31.44)$ & $100(33.33)$ & \multirow[t]{4}{*}{0.077} \\
\hline 1 day per week & $35(11.71)$ & $55(18.33)$ & \\
\hline 2-6 days per week & $117(39.13)$ & $118(39.33)$ & \\
\hline Every day & $53(17.73)$ & $27(9.00)$ & \\
\hline \multicolumn{4}{|l|}{ Weight-for-age percentile } \\
\hline Lowest & $71(23.75)$ & $79(26.33)$ & \multirow[t]{4}{*}{0.712} \\
\hline 2 & $72(24.08)$ & $74(24.67)$ & \\
\hline 3 & $77(25.75)$ & $67(22.33)$ & \\
\hline Highest & $79(26.42)$ & $80(26.67)$ & \\
\hline Child dental visit since Wave I & $212(70.90)$ & $190(63.33)$ & 0.029 \\
\hline Current participation in head start & $62(20.74)$ & 47 (15.67) & 0.097 \\
\hline \multicolumn{4}{|l|}{ New caries between $\mathrm{W} 1$ and $\mathrm{W} 2$} \\
\hline Noncavitated lesions & 3.50 & 3.45 & 0.758 \\
\hline Lowest & $84(28.09)$ & $85(28.33)$ & \multirow[t]{4}{*}{0.844} \\
\hline 2 & $31(10.37)$ & $31(10.33)$ & \\
\hline 3 & $109(36.45)$ & $105(25.00)$ & \\
\hline Highest & $75(25.08)$ & $79(26.33)$ & \\
\hline Cavitated lesions & 2.15 & 2.14 & 0.508 \\
\hline Lowest & $178(59.53)$ & $179(59.67)$ & 0.936 \\
\hline 2 & $43(14.38)$ & $51(17.00)$ & \\
\hline Highest & $78(26.09)$ & $70(23.33)$ & \\
\hline Total untreated lesions & 5.65 & 5.59 & 0.572 \\
\hline Lowest & $72(24.08)$ & $78(26.00)$ & 0.404 \\
\hline 2 & $53(17.73)$ & $42(14.00)$ & \\
\hline 3 & $91(30.43)$ & $101(33.67)$ & \\
\hline Highest & $83(27.76)$ & $79(26.33)$ & \\
\hline \multicolumn{4}{|l|}{ Caregiver/family characteristics } \\
\hline \multicolumn{4}{|l|}{ Caregiver change } \\
\hline Wave 2 to Wave 3 & $7(2.34)$ & $5(1.67)$ & 0.590 \\
\hline \multicolumn{4}{|l|}{ Gender } \\
\hline Male & $11(3.68)$ & $16(5.33)$ & \multirow[t]{2}{*}{0.204} \\
\hline Female & $288(96.32)$ & $284(94.67)$ & \\
\hline \multicolumn{4}{|l|}{ Age } \\
\hline 14-24 years & $63(21.07)$ & $71(23.67)$ & \multirow[t]{4}{*}{0.705} \\
\hline 25-34 years & $145(48.49)$ & $150(50.00)$ & \\
\hline 35-44 years & $64(21.40)$ & $51(17.00)$ & \\
\hline $45+$ years & $27(9.03)$ & $28(9.33)$ & \\
\hline \multicolumn{4}{|l|}{ Highest Education Level } \\
\hline Less than high school & $146(48.83)$ & $127(42.33)$ & 0.077 \\
\hline High school/GED & 89 (29.77) & $102(34.00)$ & \\
\hline Some college or more & $64(21.40)$ & $71(23.67)$ & \\
\hline Household income & & & \\
\hline$<\$ 10 \mathrm{~K}$ & $118(39.46)$ & $113(37.67)$ & 0.369 \\
\hline$\$ 10-\$ 19999$ & $91(30.43)$ & $82(27.33)$ & \\
\hline$\$ 20-\$ 29999$ & $51(17.06)$ & $60(20.00)$ & \\
\hline$\$ 30 \mathrm{~K}$ or more & $39(13.04)$ & $45(15.00)$ & \\
\hline
\end{tabular}


Table 1. Continued

\begin{tabular}{|c|c|c|c|}
\hline & $\begin{array}{l}\mathrm{MI}+\mathrm{DVD} \\
n(\%)\end{array}$ & $\begin{array}{l}\text { DVD-only } \\
n(\%)\end{array}$ & $P$ \\
\hline \multicolumn{4}{|l|}{ Oral health self-efficacy } \\
\hline Lowest & $86(28.76)$ & $84(28.00)$ & \multirow[t]{4}{*}{0.876} \\
\hline 2 & $68(22.74)$ & $76(25.33)$ & \\
\hline 3 & $75(25.08)$ & $76(25.33)$ & \\
\hline Highest & $70(23.41)$ & $64(21.33)$ & \\
\hline \multicolumn{4}{|l|}{ Parenting stress } \\
\hline Lowest & $98(32.78)$ & $90(30.00)$ & \multirow[t]{4}{*}{0.148} \\
\hline 2 & $66(22.07)$ & $68(22.67)$ & \\
\hline 3 & $62(20.74)$ & $75(25.00)$ & \\
\hline Highest & $73(24.41)$ & $67(22.33)$ & \\
\hline Fatalism & $233(77.93)$ & $216(72.00)$ & 0.182 \\
\hline Religious services at least $1 \times$ per week & $87(29.10)$ & $90(30.00)$ & 0.966 \\
\hline \multicolumn{4}{|l|}{$\mathrm{D}_{\mathrm{T}} \mathrm{MFS}$} \\
\hline Lowest & $78(26.74)$ & $85(28.72)$ & \multirow[t]{4}{*}{0.472} \\
\hline 2 & $69(23.63)$ & $71(23.99)$ & \\
\hline 3 & $73(25.00)$ & $77(26.01)$ & \\
\hline Highest & $72(24.66)$ & $63(21.28)$ & \\
\hline \multicolumn{4}{|c|}{ Brushing behaviors } \\
\hline \multicolumn{4}{|c|}{ Times child brushes per day in a typical week } \\
\hline$<2 \times$ per day & $131(43.81)$ & $158(52.67)$ & \multirow[t]{2}{*}{0.017} \\
\hline $2 \times$ per day & $168(56.19)$ & $142(47.33)$ & \\
\hline \multicolumn{4}{|c|}{ Days child brushes per week in a typical week } \\
\hline$<7$ days & $71(23.75)$ & $67(22.33)$ & \\
\hline 7 days & $228(76.25)$ & $232(77.33)$ & \\
\hline \multicolumn{4}{|c|}{ Days child brushes at bedtime in a typical week } \\
\hline$<7$ days & $196(65.55)$ & $224(74.67)$ & \multirow[t]{2}{*}{0.047} \\
\hline 7 days & $103(34.45)$ & $76(25.33)$ & \\
\hline \multicolumn{4}{|l|}{ Oral health practices } \\
\hline \multicolumn{4}{|l|}{ Provides child with nonsugared snacks } \\
\hline $\mathrm{No}^{\mathrm{a}}$ & $30(10.03)$ & $27(9.00)$ & \multirow[t]{2}{*}{0.816} \\
\hline Yes & $269(89.97)$ & $273(91.00)$ & \\
\hline \multicolumn{4}{|l|}{ Gives child healthy meals } \\
\hline No & $14(4.68)$ & $26(8.67)$ & \multirow[t]{2}{*}{0.129} \\
\hline Yes & $285(95.32)$ & $274(91.33)$ & \\
\hline \multicolumn{4}{|l|}{ Checks child for precavities } \\
\hline No & $122(40.80)$ & $127(42.33)$ & \multirow[t]{2}{*}{0.746} \\
\hline Yes & $177(59.20)$ & $173(57.67)$ & \\
\hline \multicolumn{4}{|l|}{ Makes sure child sees DDS every 6 mos } \\
\hline No & $126(42.14)$ & $143(47.67)$ & \multirow[t]{2}{*}{0.142} \\
\hline Yes & $173(57.86)$ & $157(52.33)$ & \\
\hline \multicolumn{4}{|l|}{ Makes sure child brushes at bedtime } \\
\hline No & $113(37.79)$ & $123(41.00)$ & \multirow[t]{2}{*}{0.221} \\
\hline Yes & $186(62.21)$ & $177(59.00)$ & \\
\hline \multicolumn{4}{|l|}{ Makes sure child brushes $2 \times$ per day } \\
\hline No & $116(38.80)$ & $132(44.00)$ & 0.079 \\
\hline Yes & $183(61.20)$ & $168(56.00)$ & \\
\hline
\end{tabular}

'The No and Yes categories are based on the caregivers' responses to questions by selecting one of these two answers: 'I do this now' or 'I do not do this now'.

behavioral outcomes. Final baseline predictors were identified as those characteristics differing significantly between the two intervention groups (Table 1). A measure of self-efficacy and an indicator for group assignment were included as a predictor. The impact of the intervention on the 6-month preliminary outcomes is presented in Table 2. Controlling for caregiver change between Wave I and II, neighborhood disadvantage, having ever visited a dentist, brushing twice per day, brushing every day at bedtime, and self-efficacy, the intervention group assignment only had a significant impact on whether or not the caregiver reported checking the child for precavities and making sure the child sees the dentist every 6 months. Those caregivers in the MI + DVD group were 3.6 times as likely to report checking for precavities and 2 times more likely to report making sure the child sees the 


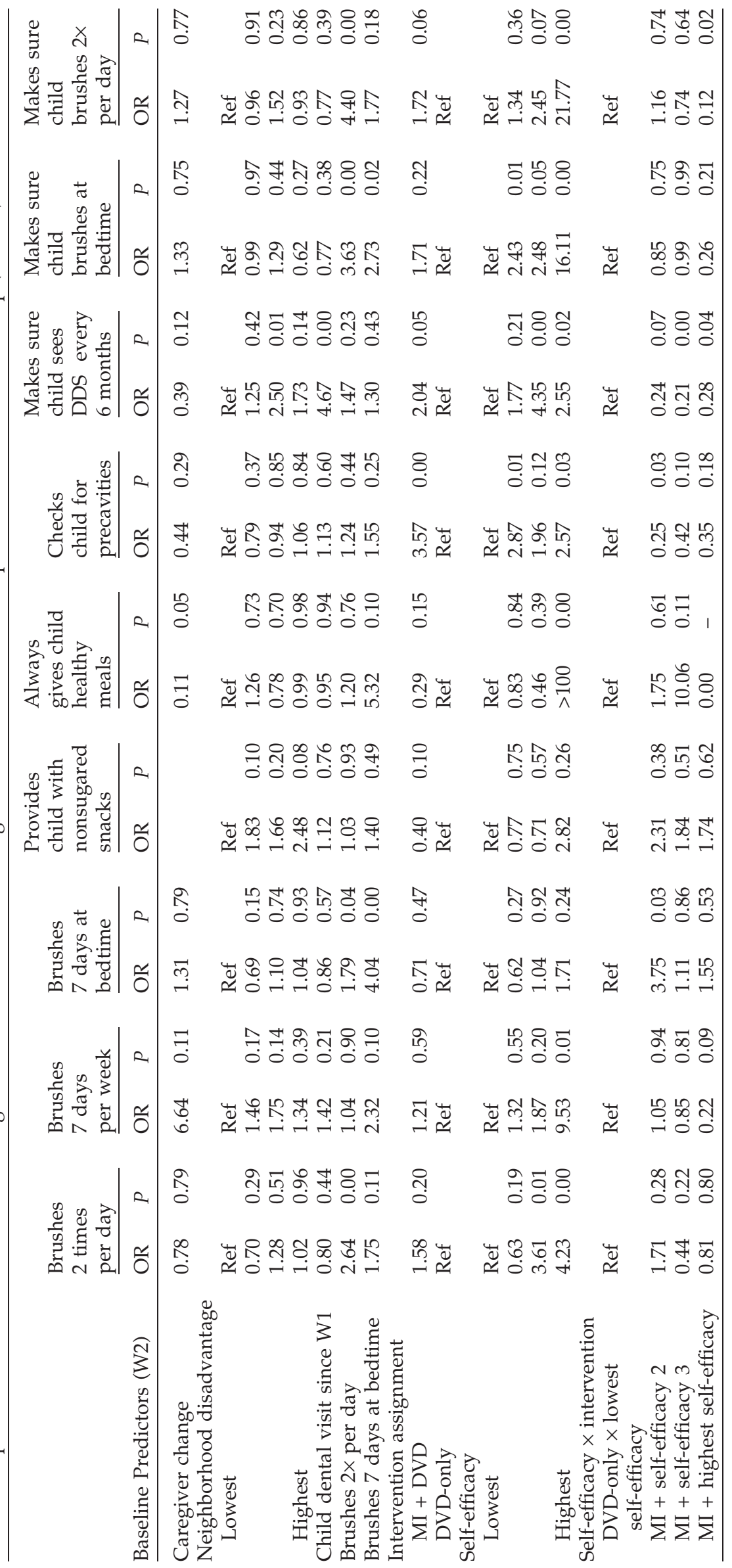


dentist every 6 months than those caregivers in the DVD-only group.

The impact of the intervention on four additional outcomes was in the expected direction; however, these results failed to reach significance. Caregivers in the MI + DVD group reported: (i) that the child brushes twice per day (OR = 1.6); (ii) that the child brushes 7 days per week $(\mathrm{OR}=1.2)$; (iii) that the child brushes every day at bedtime $(\mathrm{OR}=1.7)$; and (iv) making sure that the child brushes twice per day $(\mathrm{OR}=1.7)$.

\section{Wave III final behavioral outcomes}

Logistic regression models were also used to test the impact of the intervention on the Wave III behavioral outcomes. Final baseline predictors for the Wave III outcomes models were identified in the same manner as those for the 6-month outcomes. The impact of the intervention on the Wave III behavioral outcomes is presented in Table 3 . Accounting for caregiver change between Wave I and II, neighborhood disadvantage, having ever visited a dentist, brushing twice per day, brushing every day at bedtime, and self-efficacy, caregivers in the MI + DVD group were significantly more likely $(\mathrm{OR}=2.7)$ than those in the DVD-only group to report checking their child for precavities. Behavioral outcomes where the impact was on the expected direction yet failed to reach significance include: (i) reporting that the child brushes twice per day $(\mathrm{OR}=1.2)$; (ii) reporting that the child brushes everyday at bedtime $(\mathrm{OR}=1.1)$; (iii) making sure the child sees the dentist every 6 months (OR = 1.2); (iv) making sure the child brushes at bedtime $(\mathrm{OR}=1.6)$; and (v) making sure the child brushes twice per day ever day $\mathrm{OR}=1.5$ ).

\section{Wave III clinical outcomes}

At Wave III, the MI + DVD group developed on average 4.0 new noncavitated lesions and 2.5 new cavitated lesions. The DVD-only group developed on average 4.1 new noncavitated lesions and 2.3 new cavitated lesions. The results of the negative binomial models show no main effect of the intervention on the development of new noncavitated, cavitated, and total new untreated disease (Table 4). Also, no significant interaction between intervention group assignment and baseline disease level or level of selfefficacy and intervention assignment was found.

\section{Secondary analysis of potential moderators}

Even though the subsample of taped sessions was small $(n=152)$, we conducted a secondary analysis of only those caregivers who received MI and whose sessions were rated using the MITI to determine whether the fidelity of the MI session could moderate the effects of the intervention. When the MI fidelity summary measure was included along with baseline caries severity and self-efficacy, no significant impact of fidelity was observed on either the final clinical outcomes or the 6-month and final behavioral outcomes (results not shown).

\section{Discussion}

This clinical trial of MI for caregivers of urban children was conducted to (i) confirm the effectiveness of MI with caregivers in promoting good oral health in a 'real-world' trial, and (ii) examine the use of this approach with an extremely low-income, highrisk urban sample. In this relatively large study, we found significant intervention-related effects for only 1 of 9 behavioral outcomes evaluated at each followup point (approximately 6 months and 2 years) and found no effects on dental caries. This large study does not support the findings reported by Weinstein et al. (23) and Harrison et al. (52). One potential difference between this study and those reported earlier is that we did not discuss specific goals from a menu of potential oral health behaviors with each caregiver, as was described by Weinstein et al. (23). Another difference is that in this study dental care was not provided and is not readily accessible in the community, as is the case in areas where Native Canadians live (52). The lack of dental providers in Detroit is a major problem facing our families. For a city where over half of the population live in poverty or near poverty, there were four community clinic and a small network of private dentists serving over 300000 children. The lack of preventive care in Detroit is in contrast to the finding reported by Weinstein et al. $(23,52)$. We contend that the impact of MI on dental caries development in the other studies was related to the increase in compliance with professional fluoride varnish applications by the caregivers in the intervention group.

This finding is inconsistent with the larger literature on MI for health-related behaviors, as well as with the few studies looking specifically at the use of MI for promoting caregiver use of good oral health practices with their children. There are a number of possible reasons for this inconsistency. First, there is growing evidence that even extended assessment can have clear effects on the behavior being measured and that this phenomenon can mask inter- 


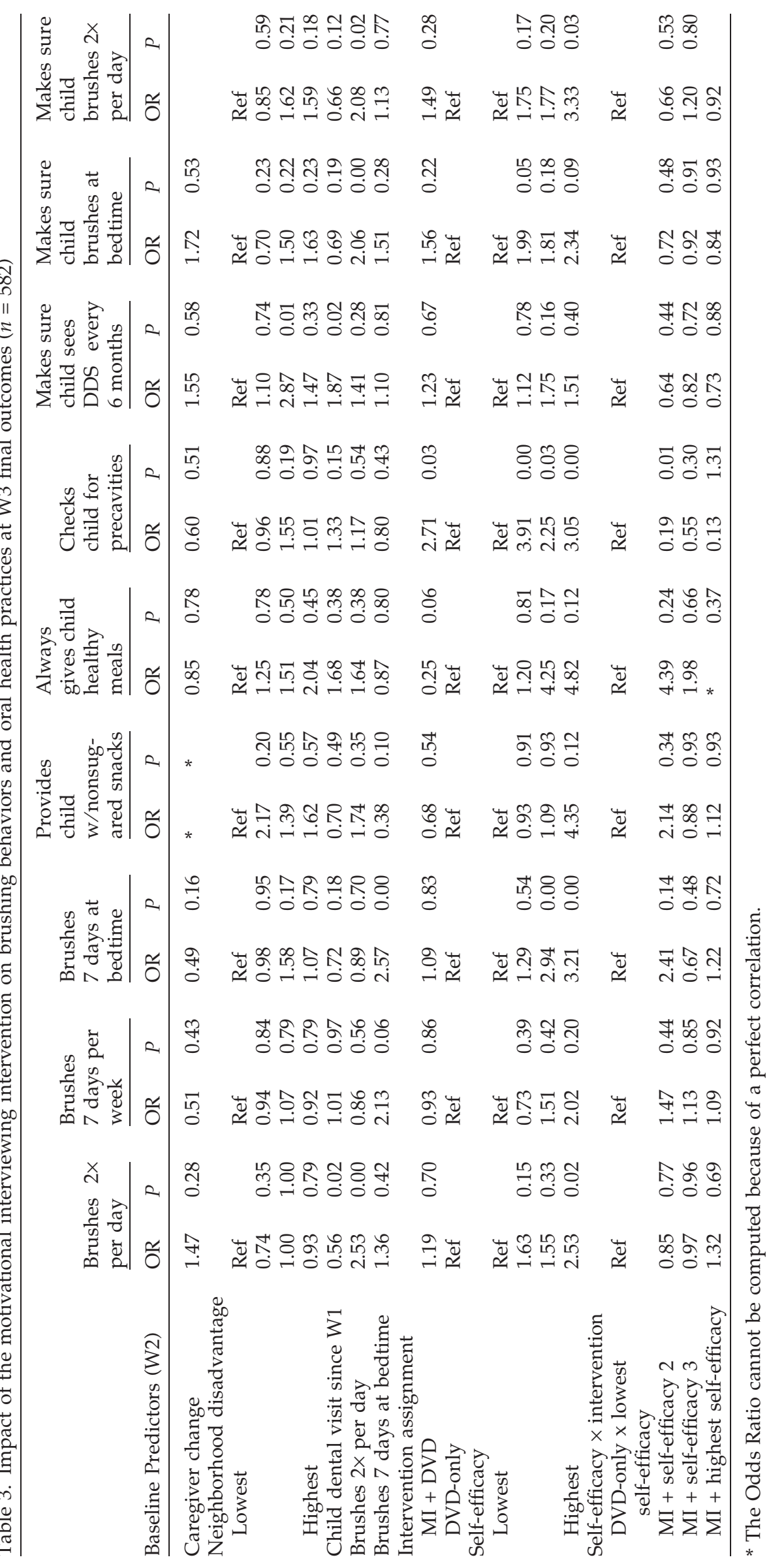




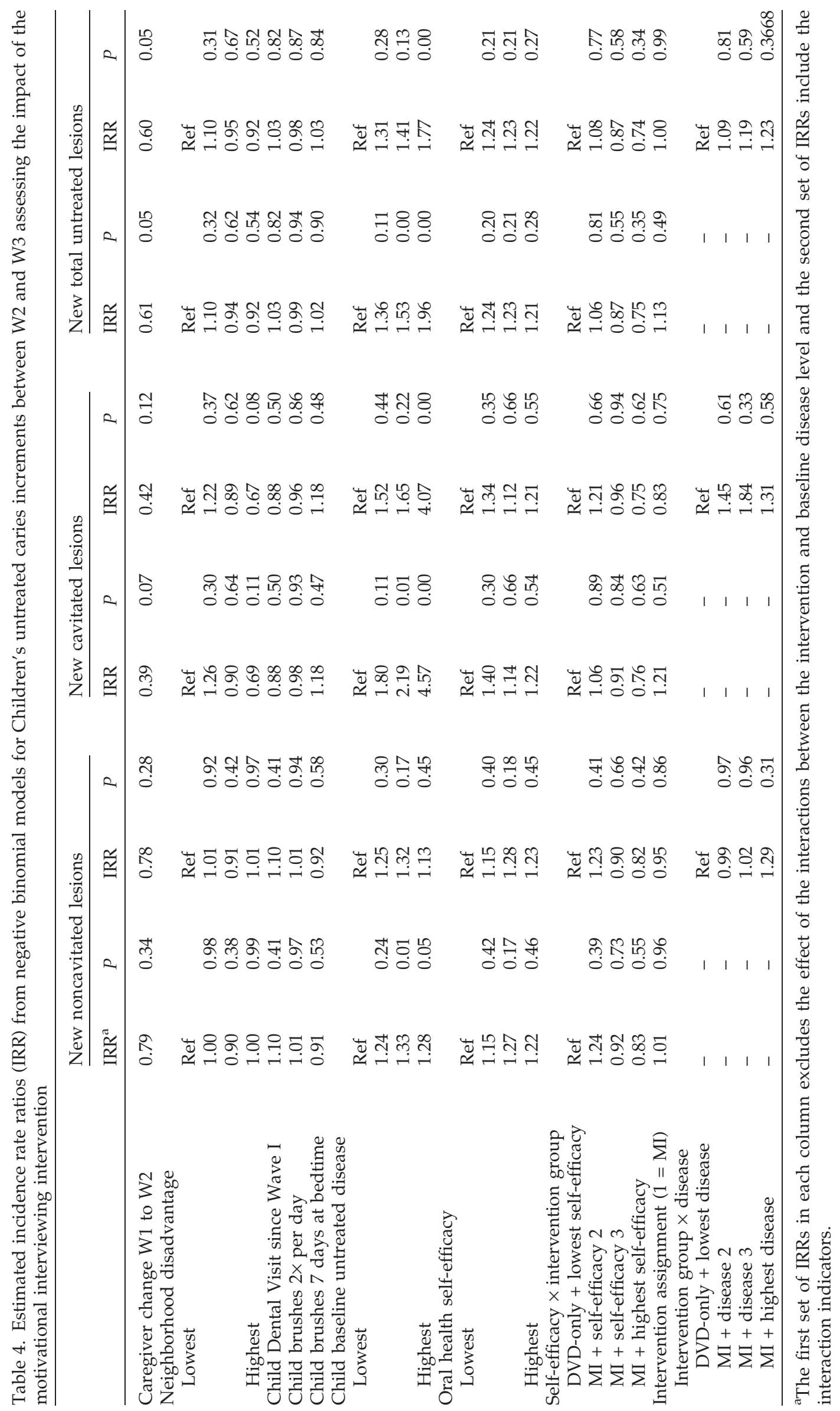


vention effects in controlled trials of brief interventions (52-59). Viewed from this perspective, the highly intensive assessment and monitoring of oral health conducted with all participants in this sample may have led to a general effect that limited the ability of the brief motivational intervention to show incremental efficacy. The use of a very strong control condition (a high-quality 15-minute video) may have exacerbated this effect. Clearly, the control group in this study received far more attention and care than is the norm for other low-income urban children and caregivers.

Second, fidelity to the MI model was modest. Previous studies have shown associations between MI fidelity and outcomes (60). A number of previous studies have demonstrated the challenges involved in obtaining full fidelity to the MI approach among community providers (61-63).

Third, a number of studies have suggested that MI may be ineffective or even counter-productive with participants who are already motivated to make changes in the target behavior. The present study presented a motivational intervention to participants in the MI + DVD group regardless of baseline motivation, which could have resulted in mixed effects as a function of initial readiness to change.

Fourth, as opposed to previous studies using a similar approach, this sample focused exclusively on very low-income African-American caregivers and their children. Previous studies by Weinstein $(12,23,28)$ focused on a low-income sample, but was restricted to Asian and Mexican-American immigrants. Evidence from comparative studies suggests that these groups may differ in their response to motivational interviewing (25). Additionally, the sample utilized in the present study also differed in access to subsequent dental care from the samples included in the previous studies.

Finally, MI in other contexts relies heavily on facilitating a very personal analysis of the pros and cons of the present behavior. In contrast to behaviors such as substance abuse, poor diet, or poor medication adherence-all of which have clear and personally salient negative effects-the oral health of one's child may be less clearly relevant, particularly for caregivers who are multiply stressed.

The current study did not find that caregivers who participated in the MI intervention were more likely to report brushing their children's teeth at bedtime. The broad nature of the specific changes promoted in this study may have inhibited the ability to have an impact on specific oral health behaviors. We predict that the reason for this finding is the emphasis in the project and the DVD on the 'precavities' and how they can be prevented from progressing to 'cavitities'. The repetition of the message over the 3 waves of data collection and the DVD and the MI session may have led to this finding.

Dental caries is a complex disease and is caused by a complex interplay of risk factors at the tooth, mouth, family, and community levels (64). It is not possible for one intervention to sustain long-term reduction in the disease. As a biofilm-initiated disease, preventing the development of the disease requires constant daily adherence to self-care at home and changing the biofilm ecology. Professional care is necessary but not sufficient for longterm prevention of dental caries. MI has been designated a promising effective method to prevent dental disease (65) and can influence both selfand professional care behaviors related to dental caries. To fully develop this tool, there is a need to understand how best to customize MI to diverse clinical conditions and population group. Also, there is a need to evaluate how MI can be delivered to impact on disease conditions that are not critical or life-threatening like drug or alcohol abuse and HIV infections. There is also a need for research on what aspects of the MI process (change talk, discrepancy, readiness to change, urgency of change, ability to change, and barriers to change) can be influential on the behavioral change process. The change process is not a singular event, but rather a series of small steps that are interrupted by periods of remissions or relapse. The frequency and intensity of the MI tools may need to be adjusted to the stage in the process of change, commitment to change, and life events. Research is needed in this area.

This study found that after 2 years caregivers who participated in an MI session that lasted around 40 minutes with one brief telephone booster within 7 months postintervention reported more often than those in the comparison group that they check their child for precavities. Other behaviors were also more frequently reported, but did not reach statistical significance, by those in the MI session than those in the other group including the child brushing twice a day, the child brushing every day at bedtime, making sure the child sees the dentist every 6 months, making sure the child brushes at bedtime, and making sure that the child brushes twice per day. The study did not find any clinical nor statistically significant difference in the development of untreated caries in children. 


\section{Acknowledgments}

This study was supported with funding from the National Institute of Dental and Craniofacial Research (NIDCR Grant no. U-54 DE 14261-01, the Delta Dental Fund of Michigan, and the University of Michigan's Office of Vice Presidential Research.

\section{References}

1. Dye BA, Tan S, Smith V, Lewis BG, Barker LK, Thornton-Evans G et al. Trends in oral health status: United States, 1988-1994 and 1999-2004. National Center for Health Statistics. Vital Health Stat 2007;11:114-88.

2. Peretz B, Ram D, Azo E, Efrat Y. Preschool caries as an indicator of future caries: a longitudinal study. Pediatr Dent 2003;25:114-88.

3. Albert DA, Findley S, Mitchell D, Park K, McManus JM. Dental caries among disadvantaged 3- to 4-yearold children in northern Manhattan. Pediatr Dent 2002;24:229-33.

4. Autio JT, Tomas SI. Prevalence of noncavitated and cavitated carious lesions in 5-year-old Head Start schoolchildren in Alachua County, Florida. Pediatr Dent 2005;27:54-60.

5. Greer MHK, Tengan SL, Hu KI, Takata JT. Early childhood caries among Hawaii public school children, 1989 vs. 1999. Pac Health Dialog 2003;10:1722.

6. Ismail AI, Lim S, Sohn W, Willem JM. Determinants of early childhood caries in low-income AfricanAmerican young children. Pediatr Dent 2008;30:28996.

7. Jigjid B, Ueno M, Shinada K, Kawaguchi Y. Early childhood caries and related risk factoirs in Mongolian children. Community Dent Health 2009;26:121-8.

8. Psoter WJ, Pendrys DG, Morse DE, Zhang H, Mayne ST. Association of ethnicity/race and socioeconomic status with early childhood caries patterns. J Public Health Dent 2006;66:23-9.

9. Tiano AV, Moimaz SA, Saliba O, Saliba NA. Dental caries prevalence in children up to 36 months of age attending daycare centers in municipalities with different water fluoride content. J Appl Oral Sci 2009;17:39-44.

10. Broadbent JM, Thomson WM, Williams SM. Does caries in primary teeth predict enamel defects in permanent teeth? A longitudinal study. J Dent Res 2005;84:260-4.

11. Edelstein BL, Douglass CW. Dispelling the myth that 50 percent of US schoolchildren have never had a cavity. Public Health Rep 1995;110:522-30.

12. Weinstein $\mathrm{P}$, Harrison $\mathrm{R}$, Benton $\mathrm{T}$. Motivating parents to prevent caries in their young children: one year findings. J Am Dent Assoc 2004;135:731-8.

13. Nield LS, Stenger JP, Kamat D. Common pediatric dental dilemmas. Clin Pediatr 2008;47:99-105.

14. Grindefjord M, Dahllöf G, Modéer T. Caries development in children from 2.5 to 3.5 years of age: a longitudinal study. Caries Res 1995;29:449-54.

15. Harris R, Nicoll AD, Adair PM, Pine CM. Risk factors for dental caries in young children: a systematic review of the literature. Community Dent Health 2004;21(Supplement):71-85.

16. Law V, Seow WK. A longitudinal controlled study of factors associated with mutans streptococci infection and caries lesion initiation in children 21-72 months old. Pediatr Dent 2006;28:58-65.

17. Yonezu T, Machida Y. Caries development in children 1.5 to 3 years of age: a longitudinal study. Bull Tokyo Dent Coll 1998;39:25-9.

18. Neuhauser L, Constantine WL, Constantine NA, Sokal-Gutierrez K, Obarski SK, Clayton L et al. Promoting prenatal and early childhood health: evaluation of a statewide, material-based intervention for parents. Am J Public Health 2007;97:1813-9.

19. Johnsen DC. Characteristics and backgrounds of children with nursing caries. Pediatr Dent 1982;4: 218-24.

20. Febres C, Echeverri EA, Keene HJ. Parental awareness, habits, and social factors and their relationship to baby bottle tooth decay. Pediatr Dent 1997;19:22-7.

21. Kay EJ, Logam HL, Jakobsen J. Is dental health education effective? Systematic review of current evidence. Community Dent Oral Epidemiol 1996;24:231-5.

22. Reisine S, Litt M. Social and psychological theories and their use for dental practice. Int Dent J 1993; 43:279-87.

23. Weinstein P, Domoto P, Wohlers K, Koday M. Mexican-American parents with children at risk for baby bottle tooth decay: pilot study at a migrant farm workers clinic. J Dent Child 1992;59:378-88.

24. Rollnick S, Miller WR. What is Motivational Interviewing? Behav Cogn Psychother 1995;23:325-34.

25. Hettema JE, Steele JM, Miller WR. Motivational Interviewing. Annu Rev Clin Psychol 2005;1:91-111.

26. Dunn C, Deroo L, Rivara FP. The use of brief interventions adapted from motivational interviewing across behavioral domains: a systematic review. Addiction 2001;96:1725-42.

27. Vasilaki EI, Hosier SG, Miles Cox X. The efficacy of motivational interviewing as a brief intervention for excessive drinking: a meta-analytic review. Alcohol Alcohol 2006;41:328-35.

28. Weinstein P, Harrison R, Benton T. Motivating mothers to prevent caries: confirming the beneficial effect of counseling. J Am Dent Assoc 2006;137:789-93.

29. Freudenthal JJ. Motivational Interviewing as an intervention for early childhood caries risk-related behaviors. J Dent Hyg 2008;82:1.

30. Freudenthal JJ, Bowen DM. Motivational interviewing to decrease parental risk-related behaviors for early childhood caries. J Dent Hyg 2010;84:29-34.

31. Erickson SJ, Gerstle M, Feldstein SW. Brief interventions and motivational interviewing with children, adolescents, and their parents in pediatric health care settings. Arch Pediatr Adolesc Med 2005;59:1173-80.

32. Kumpfer KL, Alvarado R. Family-strengthening approaches for the prevention of youth problem behaviors. Am Psychol 2003;58:457-65.

33. Nutbeam D, Aar L, Catford J. Understanding children's health behavior: the implications for health promotion for young people. Soc Sci Med 1989;29: 317-25.

34. Perry CL, Luepker RV, Murray DM, Kurth C, Mullis $\mathrm{R}$, Crockett $\mathrm{S}$ et al. Parent involvement with chil- 
dren's health promotion: the Minnesota Home Team. Am J Public Health 1988;78:1156-60.

35. Case A, Paxson C. Parental behavior and child health. Health Aff 2002;21:164-78.

36. Ismail AI, Sohn W, Tellez M, Willem JM, Betz J, Lepkowski J. Risk indicators for dental caries using the International Caries Detection and Assessment System. Community Dent Oral Epidemiol 2008;36: 55-68.

37. Bandura A. Social foundations of though and action: a social cognitive. Englewood Cliffs, NJ: Prentice Hall; 1986.

38. Moyers TB, Martin T, Manuel JK, Hendrickson SML, Miller WR. Assessing competence in the use of motivational interviewing. J Subst Abuse Treat 2005; 28:19-26.

39. Finlayson TL, Siefert K, Ismail AI, Sohn W. Psychosocial factors and oral health among low-income African-American children in Detroit. Community Dent Oral Epidemiol 2007;35:439-48.

40. Finlayson TL, Siefert K, Ismail AI, Sohn W. Maternal self-efficacy and 1-5 year old children's brushing habits. Community Dent Oral Epidemiol 2007;35: 272-81.

41. Burt B, Kolker J, Sandretto A, Yuan Y, Sohn W, Ismail AI. Dietary patterns related to caries in a low-income adult population. Caries Res 2006;40:473-80.

42. Kolker JL, Burt B, Sandretto AM, Yuan Y, Sohn W, Lang $S$ et al. Dental caries and dietary patterns in low-income African-American children. Pediatr Dent 2007;29:457-64.

43. Lim S, Sohn W, Burt BA, Sandretto AM, Kolker JL, Marshall TA et al. Cariogenicity of soft drinks, milk, and fruit juice in low income African-American children: a longitudinal study. J Am Dent Assoc 2008;39:959-67.

44. Ismail AI, Sohn W, Lim S, Willem JM. Predictors of dental caries progression in primary teeth. J Dent Res 2009;88:270-5.

45. Tellez M, Burt BA, Sohn W, Ismail AI. Assessment of the relationship between neighborhood characteristics and dental caries severity among low-income African Americans: a multilevel approach. J Public Health Dent 2006;66:30-6.

46. Kuczmarski RJ, Ogden CL, Grummer-Strawn LM, Flegal KM, Guo SS, Wei R et al. CDC growth charts: United States. Advance data from vital and health statistics, no. 314. Hyattsville, MD: National Center for Health Statistics; 2000.

47. Ismail AI, Sohn W, Tellez M, Amaya A, Sen A, Hasson $\mathrm{H}$ et al. The International Caries Detection and Assessment System (ICDAS): an integrated system for measuring dental caries. Community Dent Oral Epidemiol 2007;35:170-8.

48. Abidin R. Parenting stress index, 3rd edn. Odessa, TX: Psychological Assessment Resources, Inc; 1995.

49. Ross CE, Mirowsky J. Neighborhood disadvantage, disorder, and health. J Health Soc Behav 2001;42:25876.

50. Beck JD, Lawrence HP, Koch GG. A method for adjusting caries increments for reversals due to examiner misclassification. Community Dent Oral Epidemiol 1995;23:321-30.
51. Raghunathan TL, Lepkowski JM, Van Hoewyk J, Solenberger P. A multivariate technique for multiply imputing missing values using a sequence of regression models. Surv Methodol 2001;27:85-95.

52. Harrison R, Benton T, Everson-Stewart S, Weinstein P. Effect of motivational interviewing on rates of early childhood caries: a randomized trial. Pediatr Dent 2007;29:16-22.

53. Miller WR, Yahne CE, Moyers TB, Martinez J, Pirritano M. A randomized trial of methods to help clinicians learn motivational interviewing. J Consult Clin Psychol 2004;72:1050-62.

54. Epstein EE, Drapkin ML, Yusko DA, Cook SM, McCrady BS, Jensen NK. Is alcohol assessment therapeutic? Pretreatment change in drinking among alcohol-dependent women. J Stud Alcohol 2005;66: 369-78.

55. Moyer A, Finney JW, Swearingen CE, Vergun P. Brief interventions for alcohol problems: a meta-analytic review of controlled investigations in treatmentseeking and non-treatment-seeking populations. Addiction 2002;97:279-92.

56. Burke BL, Arkowitz H, Menchola M. The efficacy of motivational interviewing: a meta-analysis of controlled clinical trials. J Consult Clin Psychol 2003;71: 843-61.

57. Kaner EF, Beyer F, Dickinson HO, Pienaar E, Campbell F, Schlesinger $\mathrm{C}$ et al. Effectiveness of brief alcohol interventions in primary care populations. Cochrane Database Syst Rev 2007;2:CD004148.

58. Winhusen T, Kropp F, Babcock D, Hague D, Erickson SJ, Renz C et al. Motivational enhancement therapy to improve treatment utilization and outcome in pregnant substance users. J Subst Abuse Treat 2008; 35:161-73.

59. Kypri K, Langley JD, Saunders JB, Cashell-Smith ML. Assessment may conceal therapeutic benefit: findings from a randomized controlled trial for hazardous drinking. Addiction 2007;102:62-70.

60. Martino S, Ball SA, Nich C, Frankforter TL, Carroll KM. Community program therapist adherence and competence in motivational enhancement therapy. Drug Alcohol Depend 2008;96:37-48.

61. Baer JS, Rosengren DB, Dunn CW, Wells EA, Ogle RL, Hartzler B. An evaluation of workshop training in motivational interviewing for addiction and mental health clinicians. Drug Alcohol Depend 2004;73: 99-106.

62. Miller WR. A small study of training in motivational interviewing: does one workshop change clinician and client behavior? Behav Cogn Psychother 2001;29:457-71.

63. Moyers TB, Manuel JK, Wilson PG, Hendrickson SML, Talcott W, Durand P. A randomized trial investigating training in motivational interviewing for behavioral health providers. Behav Cogn Psychother 2008;36:149-62.

64. Selwitz RH, Ismail AI, Pitts NB. Dental caries. Lancet 2007;369:51-9.

65. Yevlahova D, Satur J. Models for individual oral health promotion and their effectiveness: a systematic review. Aust Dent J 2009;64:190-7. 